\title{
FREQUENCY AND FACTORS ASSOCIATED WITH INJURY TO THE AXILLARY VEIN IN WOMEN THAT UNDERWENT AXILLARY LYMPHADENECTOMY DURING BREAST CANCER SURGICAL TREATMENT
}

\section{Frequência e fatores associados à lesão da veia axilar em mulheres submetidas à linfadenectomia axilar no tratamento cirúrgico do câncer de mama}

\author{
Rafaela Miranda Corrêa1*, Danila Pinheiro Hubie1, Reitan Ribeiro1, \\ José Clemente Linhares', Sérgio Bruno Bonatto Hatschbach'
}

\section{ABSTRACT}

Objective: To evaluate which variables are considered risk factors associated with injury to the axillary vein during lymphadenectomy in the surgical treatment of breast cancer patients. Methods: Retrospective study performed through the electronic record analysis of 1,007 patients who underwent axillary lymph node dissection at Hospital Erasto Gaertner, from January 2010 to December 2014. We assessed the following risk factors using a standard questionnaire: age, body mass index (BMI), presence of palpable axillary metastasis in the clinical examination, sentinel lymph node pre-lymphadenectomy, presence of axillary metastasis in the perioperative period, size of metastasis and if it was adhered to axillary vessels, presence of pectoralis muscle invasion, resection of the pectoralis minor muscle, axillary incision separated from breast incision, prior radiotherapy, neoadjuvant chemotherapy, and pre and postoperative staging. For each patient who presented injury to the axillary vein, we paired them with two homogeneous controls (age, BMI, preoperative staging, surgical proposal, and neoadjuvant treatment). Results: Thirteen patients had injury to the axillary vein. In the perioperative evaluation, in most of them, the axilla was positive in the injury group (10 cases $=76.9 \%)$ and control group (12 cases $=46.1 \%$ ), and it was adhered to axillary vessels in 10 cases in the injury group (76.9\%) and 7 in the control group (26.9\%). Conclusion: In this study, the presence of axillary metastasis in the perioperative evaluation, as well as that adhered to the axillary vessels, is associated with an increased risk of injury to the axillary vein during lymphadenectomy.

KEYWORDS: Breast neoplasms; Surgery; Treatment; Lymphadenectomy; Axillary vein.

\section{RESUMO}

Objetivo: Avaliar quais variáveis se apresentam como fatores de risco associados à lesão da veia axilar durante a linfadenectomia no tratamento cirúrgico de pacientes portadoras de câncer de mama. Métodos: Estudo retrospectivo realizado por meio da análise de prontuário eletrônico de 1.007 pacientes submetidas a esvaziamento axilar no Hospital Erasto Gaertner, no período de janeiro de 2010 a dezembro de 2014. Foram avaliados, por meio de um questionário padrão, os seguintes possíveis fatores de risco: idade, índice de massa corpórea (IMC), presença de metástase axilar palpável no exame clínico, linfonodo sentinela pré-linfadenectomia, presença de metástase axilar no transoperatório, tamanho da metástase e se estava aderida aos vasos axilares, presença de invasão do músculo peitoral, ressecção do músculo peitoral menor, incisão axilar separada da incisão mamária, radioterapia prévia, quimioterapia neoadjuvante e estadiamento pré e pós-operatório. Para cada paciente que apresentou lesão de veia axilar foi realizado pareamento com dois controles homogêneos (idade, IMC, estadiamento pré-operatório, proposta cirúrgica e tratamento neoadjuvante). Resultados: Treze pacientes apresentaram lesão da veia axilar. Na avaliação transoperatória, em sua grande maioria,

Study carried out at Hospital Erasto Gaertner - Curitiba (PR), Brazil.

${ }^{1}$ Hospital Erasto Gaertner - Curitiba (PR), Brazil.

*Corresponding author: rafaelamiranda@imare.com.br

Conflict of interests: nothing to declare.

Received on: 02/23/2017. Accepted on: 06/20/2017 
a axila estava positiva no grupo da lesão ( 10 casos $=76,9 \%$ ) e no grupo controle ( 12 casos $=46,1 \%$ ) e encontrava-se aderida aos vasos axilares em 10 casos no grupo da lesão (76,9\%) e em 7 (26,9\%) no grupo controle. Conclusões: Neste estudo, a presença de metástase axilar na avaliação transoperatória, bem como aderida aos vasos axilares, está associada ao risco aumentado de lesão de veia axilar durante a linfadenectomia.

DESCRITORES: Neoplasias da mama; Cirurgia; Tratamento; Linfadenectomia; Veia axilar

\section{INTRODUCTION}

Breast cancer is more prevalent among females and represented $25.2 \%$ of all types of breast neoplasms diagnosed in women in 2015 , with about 1.67 million new cases. It is the second cause of cancer death after lung cancer in developed countries, and it is the main reason of death by the disease in developing countries with a total of 521,900 cases in general ${ }^{1}$.

Although the axillary lymphadenectomy is controversial in specific situations, it remains part of the surgical treatment in patients with invasive breast cancer and metastases in the axillary lymph nodes ${ }^{2}$. More specifically, this treatment is applicable to ill patients with $\mathrm{N} 1$ or $\mathrm{N} 2$ tumors, according to the TNM system ${ }^{3}$.

However, despite the regular public policies developed in the area and programs of mammographic tracking widely recommended for asymptomatic women with early diagnosis strategy - besides contributing to the decrease of the cancer presentation stage, also known as down-staging - , about a third of female patients in the United States suffer tumors with regional metastases (axillary lymph nodes) at the moment of diagnosis ${ }^{4,5}$.

In Brazil, according to statistics from the Brazilian Department of Health (2012), only $18 \%$ of these cancers are limited to breast in the diagnosis (pathological staging), even though efforts are done to provide mammographic coverage for all women older than 40 years ${ }^{6}$. This means that, in proportion, more patients undergo the axillary approach in Brazil than in the United States.

The conventional axillary lymphadenectomy involves resection of lymph nodes at levels I and II, as Berg7 describes. These dissections have therapeutic roles and enable staging the disease, as well as evaluating prognosis ${ }^{8}$. Unfortunately, the axillary approach is responsible for several functional sequelae due to surgical treatment, including lymphedema, paresthesia, restriction of the movement amplitude and pain in the arm ipsi laterally to dissection of lymph nodes. Although unsatisfying cosmetic results due to the approach of breast tumors may be minimized through oncoplastic surgery or through methods such as reconstruction with implants and with myocutaneous flaps, we may not do many things to repair functional sequelae 9 .

Paresthesia referred by patients is associated with the section of the intercostobrachial nerve that crosses the axilla during the lymphadenectomy. Nevertheless, this is the smallest complication and it is not a reason of complaints about limitation of quality of life in the majority of cases $^{10}$.

Lymphedema is by far the most severe intercurrence of complex clinical management with higher impact on the patient's quality of life. Studies show that the incidence rates of complications and sequelae in the arm, including lymphedema, are directly associated with radicality of the locoregional treatment ${ }^{11,12}$.

This complication that appears in 6 to $50 \%$ of the patients is associated with several risk factors: extensive surgery, number of removed lymph nodes, injury to the vessels and nerves present in the axillary content and axilla-adjuvant radiotherapy ${ }^{13-15}$.

Injury or thrombosis to the axillary vein and irreversible injury to motor nerves are very rare complications throughout the axillary lymph node dissection.

This paper aimed to determine which variables are present as risk factors associated with injury to the axillary vein during the lymphadenectomy, in the surgical treatment of a female breast cancer patient.

\section{METHODS}

We performed a retrospective study through analysis of electronic medical records from 1,007 patients who underwent axillary lymphadenectomy during the surgical treatment of breast cancer at Hospital Erasto Gaertner from January 2010 to December 2014. We evaluated the following possible risk factors of injury to the axillary vein: age, body mass index (BMI), presence of axillary metastasis palpable at preoperative period, size of axillary metastases in the perioperative period, sentinel lymph node pre-lymphadenectomy, presence of axillary metastasis adhered to axillary vessels, preservation or section of pectoralis minor muscle, axillary incision separated from breast incision, prior radiotherapy, neoadjuvant chemotherapy, and pre and postoperative staging (Appendix 1). We created two "cases and controls" samples of the same source, with the same population. Each patient that presented injury to the axillary vein was paired with two control cases, which were then compared regarding the following factors: age, BMI, preoperative staging, and proposed treatment (surgery or neoadjuvant chemotherapy).

Data were grouped in contingence tables by variable to make the statistical analysis process easier. The chi-square non-parametric test evaluated the existence of a significant difference between the levels of explanatory variables due to the answer variable.

We used another mathematical model as well. We adopted the logistic regression analysis for the statistical technique, whose main purpose is providing a mathematical equation (formula) 
that allows the investigator to replace the "X" values (studied variables) and whose result portrays their association with the outcome (in this case, injury to the axillary vein).

This model is generated through a robust sampling. Since this study had a small representative subgroup (39 patients 13 in the injury group and 26 in the control), we used a process for generating new samples called bootstrap, which creates new observations based on the initial records through a randomized sampling with replacement. Thus, we created 10,000 observations for patients with injury and value equal to 1 and another 10,000 for patients without injury (control) and value equal to 0 , with a total sample of 20,000 observations, as presented in Figure 1.

The Research Ethics Committee from Liga Paranaense de Combate ao Câncer approved the paper in August 2016.

\section{RESULTS}

We found 13 patients with injury to the axillary vein during the lymphadenectomy among the 1,007 electronic records evaluated, of whom 10 had an isolated vein injury, 2 had a vein injury associated with thoracodorsal pedicle injury and 1 had injury to the vein and long thoracic nerve. Each patient with an injury was paired with two controls, resulting in a total sample of 39 patients.

The average age of participants was 56.6 years old in the injury group and 56.7 in the control group, which varied between 40 and 82 with predominance of the fourth and fifth decades (46 and $23 \%$, respectively).

The average BMI found was $26.5 \mathrm{~kg} / \mathrm{m}^{2}$ in the injury group and $26.1 \mathrm{~kg} / \mathrm{m}^{2}$ in the control group, that varied from 18 to $40 \mathrm{~kg} / \mathrm{m}^{2}$; $61 \%$ of the patients were below $30 \mathrm{~kg} / \mathrm{m}^{2}$ and $23 \%$ were above this range.

We observed 9 cases of palpable axillary metastasis (69.2\%) during clinical examination in the group with axillary vein injury compared with 14 (53.8\%) in the control group. The Ec III-IV (27 cases $=69.2 \%$ ) and Ec I-II (12 cases $=30.7 \%)$ cases were more prevalent.

We performed the modified mastectomy according to Patey in 30 cases $(76.9 \%)$, the quadrantectomy and axillary lymphadenectomy in 8 cases (15.3\%), and 1 patient (7.6\%) underwent chest wall resection.

Only 6 (15.3\%) patients performed a biopsy of the sentinel lymph node before axillary lymph node dissection.

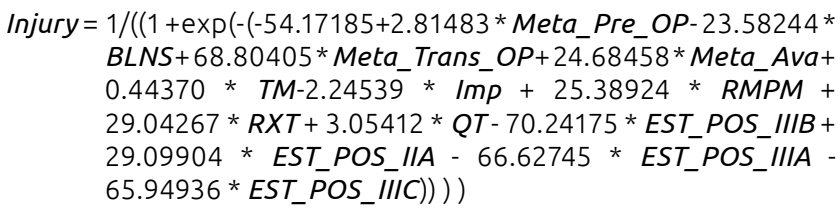

Figure 1. Mathematical model
Most of the axillae was positive in the perioperative assessment, in the injury group (10 cases $=76.9 \%$ ) and control group (12 cases $=46.1 \%$ ), and was adhered to axillary vessels in 10 cases $(76.9 \%)$ in the injury group and in 7 (26.9\%) in the control group.

This study showed that the lymph nodes were divided into size according to the largest diameter. We observed that lymph nodes measuring 1-3 cm were more prevalent $(8$ cases $=61.5 \%$ in the injury group compared with 5 cases $=19.2 \%$ in the control group), whereas those larger than $3.1 \mathrm{~cm}$ were observed in 3 cases in the injury group (23.0\%) and 4 in the control group (15.3\%).

In $6(46.1 \%)$ and $5(19.2 \%)$ cases in the injury and control group, respectively, we found invasion of the pectoralis muscle through axillary metastasis.

We observed resection of the pectoralis minor muscle during the axillary lymphadenectomy in 13 cases in the injury group (100.0\%) and 24 in the control group $(92.3 \%)$. The control group (11 cases $=$ $42.3 \%$ ) used more the axillary incision separated from the breast incision than the injury group ( 5 cases $=38.0 \%$ ).

Only 1 patient ( $7.6 \%$ ) had undergone prior radiotherapy treatment in the injury group, while the neoadjuvant chemotherapy drug was used in 8 cases in the injury group (61.5\%) and 11 in the control group (42.3\%).

Five (38.0\%) versus $13(50.0 \%)$ cases were in the I-II postoperative staging, while the 8 remaining cases $(61.5 \%)$ versus 13 cases (50.0\%) were in the Ep III-IV.

Based on Table 1, we can observe that only the variable 'presence of axillary metastasis adhered to axillary vessels' (Meta ava) showed a $1 \%$ difference of significance (or 99\% of confidence) regarding the answer variable "injury". In other words, patients with presence of axillary metastasis adhered to axillary vessels showed a higher rate of injuries, while patients without such characteristic had a smaller volume.

After using the logistic regression technique, we found that only the variable "axillary incision separated from the breast incision" (InA-InM) is not significant at a $5 \%$ level and, therefore, is removed from the mathematical model. The other variables were significant and remained ( $p$-value was smaller than 0.0001 in all of them). Being significant in a regression model reports that the variable is associated with the answer variable, i.e. explains a percentage of the answer variable. Figure 1 presents the model equation.

Based on it, the most important variable that best explains the answer variable is the "presence of axillary metastasis in the perioperative period" (Meta trans-op), followed by "postoperative staging” (Est_Pos-IIIB), according to Figure 2.

This model presented positive and validation rates of 96.26 and $97.00 \%$ respectively, as verified in Figure 1. Its predictive value was $96.26 \%$, which is an excellent result on practice. Positive and negative predictive results were also great. The sensitivity and specificity measures presented high values; therefore, the logistic regression model is classifying subjects regarding the presence or not of the answer variable "injury" as correctly. 
Table 1. Results of chi-square tests with each variable associated with injury to the axillary vein during lymphadenectomy.

\begin{tabular}{|c|c|c|c|c|}
\hline Variables & Chi-square & p-value & Result & Conclusion \\
\hline Meta pre-op & 0.3312 & 0.5650 & It accepts $\mathrm{H}_{0}$ & No significant difference \\
\hline BLS pre-EA & 0.2216 & 0.6378 & It accepts $\mathrm{H}_{0}$ & No significant difference \\
\hline Meta trans-op & 2.2029 & 0.1378 & It accepts $\mathrm{H}_{0}$ & No significant difference \\
\hline Meta ava & 6.8954 & 0.0086 & It rejects $\mathrm{H}_{0}$ & Significant difference \\
\hline $\mathrm{TM}(\mathrm{cm})$ & 0.1088 & 0.7415 & It accepts $\mathrm{H}_{0}$ & No significant difference \\
\hline IMP & 1.9152 & 0.1664 & It accepts $\mathrm{H}_{0}$ & No significant difference \\
\hline RMPM & 0.0659 & 0.7974 & It accepts $\mathrm{H}_{0}$ & No significant difference \\
\hline $\ln A-\ln M$ & 0.0132 & 0.9084 & It accepts $\mathrm{H}_{0}$ & No significant difference \\
\hline RXT pre & 2.2503 & 0.1336 & It accepts $\mathrm{H}_{0}$ & No significant difference \\
\hline QT neo & 0.0530 & 0.8179 & It accepts $\mathrm{H}_{0}$ & No significant difference \\
\hline Est pos-op & 0.4643 & 0.4956 & It accepts $\mathrm{H}_{0}$ & No significant difference \\
\hline
\end{tabular}

Meta pre-op: presence of palpable axillary metastasis at preoperative examination; BLS pre-EA: research of sentinel lymph node before axillary lymphadenectomy; Meta trans-op: presence of axillary metastasis identified at perioperative period; Meta ava: axillary metastasis adhered to the axillary vessels; TM (cm): size of the axillary metastasis in the perioperative period in centimeters; IMP: presence of axillary metastases invading the pectoralis major muscle; RMPM: resection of the pectoralis minor muscle during axillary lymphadenectomy; InA-InM: axillary incision separated from the breast incision; RXT pre: radiotherapy prior to surgery; QT neo: neoadjuvant chemotherapy; Est pos-op: postoperative staging.

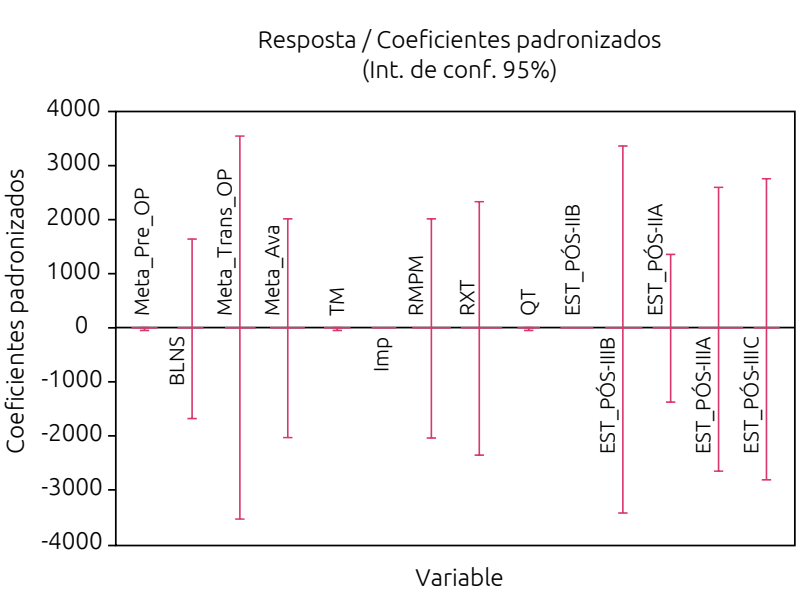

Figure 2. Explanation of each variable.

\section{DISCUSSION}

Every axilla with palpable lymph nodes should be emptied ${ }^{16}$. The only situation where axillary lymphadenectomy is not currently indicated is the presence of breast ductal carcinoma in situ, although it has a risk of axillary metastases from 0.9 to $3.8 \%$, according to several authors ${ }^{17,18}$. Another subgroup with low potential of axillary metastases is microinvasive carcinoma. Most of the papers ${ }^{19,20}$ show a $5 \%$ incidence of axillary metastases, even though Schuh et al. ${ }^{21}$ and Kinne et al. ${ }^{22}$ found axillary damage rates between 20 and $10 \%$, respectively. The different definitions of what a microinvasive or invasive tumor is would result in this frequency variation of the axillary metastasis process.

The incidence of axillary damage is closely associated with the size of the primary tumor, which is $68 \%$ in patients measuring

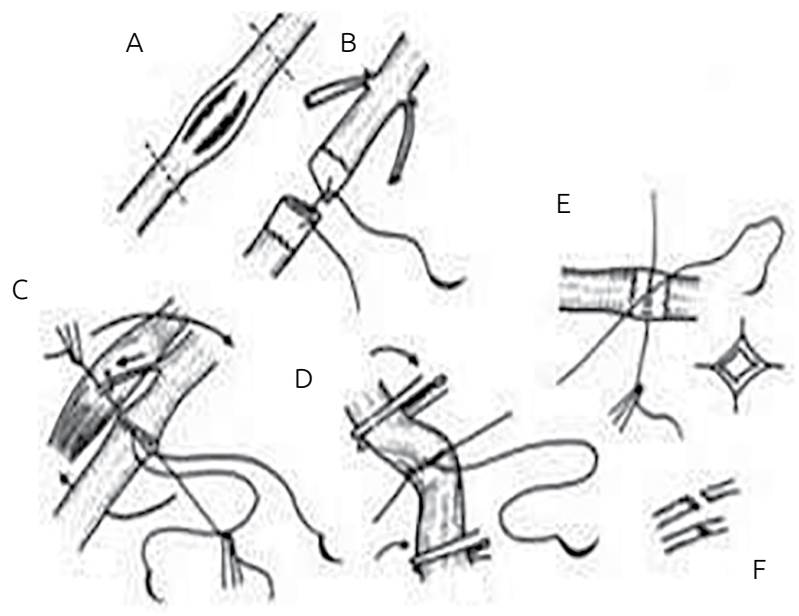

Figure 3. Vascular sutures.

between 1 and $2 \mathrm{~cm}$ of diameter, with presence of lymphatic or vascular invasion ${ }^{23}$.

Local control of breast cancer also results in increase of survival and incapacity of "cleaning" the axilla may result in difficulties to manage the disease, with distant metastases, as observed in the NSABP B- $04^{24}$ study. The incorporation of the sentinel lymph node investigation in the breast neoplasm treatment has provided many benefits to women at early stage of the disease, limited to the breast, thus avoiding axillary lymph node dissection. This treatment substantially reduced the risk of functional sequelae in the arm, which is the result of surgical manipulation, and morbidities, which cause high social, psychological, and financial costs ${ }^{25}$.

Surgical aggressive behavior is a risk factor for the development of significant morbidity, which also explains higher 
incidence of lymphedema in the postoperative period of mastectomy than in the conservative surgery ( 24 to $49 \%$ after mastectomy, and 4 to $28 \%$ after tumorectomy with axillary dissection ${ }^{26}$. An explanation would be that patients who undergo mastectomy, in general, present an advanced disease with the need of larger surgical removal of axillary lymph nodes, which are more compromised by the tumor. After surgery, weight gain may also be a risk factor ${ }^{27}$.

The dissection of axillary lymph nodes and the amount of resected and damaged lymph nodes are well known risk factors for the development of lymphedema and, at a rare scenario, injury or thrombosis of axillary vein ${ }^{28-30}$.

Vascular injuries are very important complications due to the potential risk of thrombosis, arteriovenous fistula (AV), pseudoaneurysm, functional loss of extremities, amputation, infections, and bleeding ${ }^{31,32}$.

In the beginning of the $20^{\text {th }}$ century, vessel ligation was the only kind of performed intervention, whose purposes were hemostasis or treatment of AV fistulae or aneurysms ${ }^{33}$.

Consequently, the development of anesthetic techniques, the anticoagulant possibility, blood transfusions enabling its replacement in large-sized vascular surgeries, the discovery of antibiotics suppressing a great part of the failures caused by infection and the improvement of industrial prosthetics provided a golden phase of development to the vascular surgery ${ }^{34}$.

Vessel dissection is done with common instruments to any dissection until arrival of the vessel, such as: scalpel, Metzenbaum scissors of variable size and blunt tip, rat-tooth forceps, vascular dissection clamps, and Mixter clamps with tips whose thicknesses should vary according to the kind and caliper of the dissected vessel. Anatomic knowledge of the operated area is mandatory, because orientation, in the event of an obstruction with absence of heart rate, should be given by neighboring elements ${ }^{35}$.

The incision of access is longitudinally to the vessel path. After skin, subcutaneous, fascia and separation of the muscles, we arrive at the vessel, which is always involved by a fiber adipose sheath. We may open this sheath with the help of a vascular dissection clamp and Metzenbaum scissors until reaching the vessel adventitious plane, which is followed proximal and distally up to the desired length of dissection ${ }^{36}$.

Vascular ligations are performed for simple hemostasis in cases of trauma, amputations, venous resections, and AV fistulae ligation. In the event of small vessels, a simple ligation is enough; if the vessel is larger, a transfixing suture may be performed. If the vessel must be sectioned, do it between ligations through transfixation. In cases of larger vessels (above $5 \mathrm{~mm}$ ), perform a running suture. This suture may eventually be protected by a ligation ${ }^{35}$.

We do not need anticoagulation when an artery is ligated definitely; the formation of a thrombus is foreseen that will extend until the first important proximal branch. However, when the interruption of the artery or vein is temporary, one may anticoagulant the patient with intravenous heparin in the dose of $1.5 \mathrm{mg}$ or 150 units $/ \mathrm{kg}$ of weight to promote surgical approaches on them. Half of this dose may be repeated after about two hours if the surgeon notices the formation of clots on the field. After the procedure ends, we reverse the heparin effect with protamine sulfate in the proportion of 1:1 mg in relation to the heparin $\operatorname{dose}^{37}$.

Vascular sutures should include all wall layers, and they can be done with running structure or separated sutures. The distance between the points should be $1 \mathrm{~mm}$, with a $1 \mathrm{~mm}$ depth. In general, we use 3-0 to 6-0 surgical sutures. Running suture should be made with two surgical sutures that begin in each junction and direct to the middle of the incision (Figure 3). The separated point suture, otherwise, should be used with small caliper vessels. The path must be large enough to avoid stenosis, but not so large to cause vessel enlargement, which could result in undesirable hemodynamic alterations $\mathrm{s}^{35}$.

Among the 13 mentioned cases, we observed the importance of staging in the incidence of axillary metastases: $30.7 \%$ of axillary damage in stage IIIC; $23 \%$ in stage IIIB; $7.6 \%$ in stage IIIA; and $15.3 \%$ in stage IIB. We found that axillary damage is closely associated with the primary tumor size, and it is a common event (a third of cases) as well as the most important prognosis factor. Other predictive variables of axillary metastasis, besides the tumor size, include: age, lymphatic vascular invasion, histological type, nucleal degree, histological degree, tumor grade, and location.

\section{CONCLUSION}

There are currently few studies in literature on the theme, even though much is discussed about the lymphedema, the main postoperative complication in breast surgery. Many factors have been discussed, but studies clarifying the influence of each one in the formation of lymph-lymphatic anastomosis, in compensations of the lymphatic system and in consequent repercussions on the incidence of the lymphedema still lack.

This study showed that the presence of axillary metastases in the perioperative evaluation, as well as adhered to axillary vessels, is associated with an increased risk of axillary vein injury during the axillary lymphadenectomy.

Injury or axillary vein thrombosis and injury to the axilla motor nerves are extremely rare complications. A careful surgical technique and accurate selection of patients for postoperative radiotherapy are mandatory to prevent significant morbidity after axillary lymphadenectomy. The introduction of the sentinel lymph node biopsy technique in clinical practice resulted in a significant decrease of the incidence of post-axillary lymph node dissection complications. 


\section{REFERENCES}

1. World Health Organization. International Agency for Research on Cancer. Globocan. 2015.

2. National Comprehensive Cancer Network. NCCN Clinical Practice Guidelines in Oncology:breast cancer. Version 03. 2013.

3. American Joint Committee Cancer: Breast. In: Edge SB, Byrd DR, Compton CC, Fritz AG, Greene FL, Trotti A, eds. AJCC Cancer Staging Manual. 7a edition. New York: Springer, 2010. p. 347-376.

4. Fuller MS, Lee CI, Elmore JG. Breast cancer screening: an evidence-based update.Med Clin North Am. 2015;99(3):451-68. doi: 10.1016/j.mcna.2015.01.002

5. SEER Cancer Statistics Review, 1975-2009 (Vintage 2009 Populations). Bethesda:National Cancer Institute; 2009.

6. Brasil. Ministério da Saúde. Instituto Nacional do Câncer José Alencar Gomes da Silva (INCA). Informativo Vigilância do Câncer n.2. Brasília: Ministério da Saúde; 2012.

7. Berg JW. The significance of axillary node levels in the study of breast carcinoma. Cancer. 1955;8:776-8.

8. Zarebczan DB, Neuman HB. Management of the axilla. Surg Clin North Am. 2013;93:429-44.

9. Warmuth MA, Bowen G, Prosnitz LR, Chu L, Broadwater G, Peterson B, et al. Complications of axillary lymph node dissection for carcinoma of the breast: a report based on a patient survey. Cancer. 1998;83:1362-8.

10. Salmon RJ, Ansquer Y, Asselain B. Preservation versus section of intercostal-brachial nerve (IBN) in axillary dissection for breast cancer - a prospective randomized trial. Eur J Surg Oncol. 1998;24:158-61.

11. Schünemann H, Willich N.Lymphödeme nach mammakarzinom. Dtsch Med Wochenschr. 1997;122:536-41.

12. DiSipio T, Rye S, Newman B, Hayes S. Incidence of unilateral arm lymphoedema after breast cancer: a systematic review and meta-analysis. Lancet Oncol. 2013;14:500-15.

13. Herd-Smith A, Russo A, Muraca MG, Del Turco MR, Cardona G. Prognostic factors for lymphedema after primary treatment of breast carcinoma. Cancer. 2001;92:1783-7.

14. Petrek JA, Senie RT, Peters M, Rosen PP. Lymphedema in a cohort of breast carcinoma survivors 20 years after diagnosis. Cancer. 2001;92:1368-77.

15. Kissin MW, Querci della Rovere G, Easton D,Westbury G. Risk of lymphoedema following the treatment of breast cancer. $\mathrm{Br} \mathrm{J}$ Surg. 1986;73(7):580-4.

16. Lin PP, Alison DC, WainstockJ, Miller KD, Dooley WC, Friedman $\mathrm{N}$,et al. Impact of axillary lymph node dissection on the therapy of breast cancer patients. J Clin Oncol. 1993;11:1536-44.

17. Ashikari R, Huvos AG, Snyder RE. Prospective study of noninfiltrating carcinoma of the breast. Cancer. 1977;39:435-9.

18. Solin LJ, Fowble BL, Schultz DJ, Yet IT, Kowalyshyn MJ, Goodman RL. Definitive irradiation for intraductal carcinoma of the breast. Int J Radiat Oncol Biol Phys. 1990;19:843-50.
19. Wong JH, Kopald KH, Morton DL. The impact of microinvasion on axillary node metastases and survival in patients with intraductal breast cancer. Arch Surg. 1990;125:1298-302.

20. Nevin JE, Pinzón G, Morán TJ, Baggerly JT. Minimal breast carcinoma. Am J Surg. 1980;139:357-9.

21. Schuh ME, Nemoto T, Penetrante RB, Rosner D, Dao TL. Intraductal carcinoma. Analysis of presentation, pathologic findings and outcome of disease. Arch Surg. 1986;121:1303-7.

22. Kinne DW, Petrek JA, Osborne MP, Fracchia AA, DePalo AA, Rosen PP. Breast carcinoma in situ. Arch Surg. 1989;124:33-6.

23. Chadha M, Chabon AB, Friedmann P, Vikram B. Predictors of axillary metastases in patients with $\mathrm{T} 1$ breast cancer. A multivariate analysis. Cancer. 1994;73:350-3.

24. Harris J, Ostenn R. Patients with early breast cancer benefit from effective axillary treatment. Breast Cancer Res Treat. 1985;5:17-21. doi: 10.1007/BF01807645

25. Veronesi U, Cascinelli N, Mariani L, Greco M, Saccozzi R, Luini A, etal.Twenty-year follow-up of a randomized studycomparing breast-conserving surgery with radical mastectomy for early breast cancer. N Engl J Med. 2002;347:1227-32. doi: 10.1056/ NEJMoa020989

26. Hayes SC, Janda M, Cornish B, Battistutta D, Newman B. Lymphedema after breast cancer: incidence, risk factors, and effect on upper body function. J Clin Oncol. 2008,26:3536-42.

27. Pain SJ, Vowler S, Purushotham AD. Axillaryvein abnormalities contribute to development of lymphoedema after surgery for breast cancer. Br J Surgery. 2005,92:311-5.

28. Rett MT, Lopes MCA. Fatores de risco relacionados ao linfedema. Rev Bras Mastol. 2002;12:39-42.

29. Johansson K, Ohlsson K, Ingvar C, Albertsson M, Ekdahl C. Factors associated with the development of arm lymphedema following breast cancer treatment: a match pair case-control study. Lymphology. 2002;35:59-71.

30. Rett MT, Lopes MCA. Fatores de risco relacionados ao linfedema. Rev Bras Mastol. 2002;12:39-42.

31. Andac MH. Cardiovascular Injuries, Emergency and Trauma. Ankara: Handbook; 1997. p. 229-250.

32. Andrikopoulos V, Antoniou I, Panoussis P. Arterial injuries associated with lower-extremity fractures. Cardiovasc Surg. 1995;3(1):15-8.

33. Carrel A. La téchnique opératoire des anastomoses vasculaires et la transplantation de viscères. Lyon Méd. 1902;98:859-64.

34. Carrel A. The surgery of blood vessels. Johns Hopkins Med J. 1907;18-28.

35. Brito CJ, Silva RM. Cirurgia Vascular: Cirurgia Endovascular, Angiologia. São Paulo: Revinter; 2014.

36. Rutherford RB. Atlas of vascular surgery: basic techniques and exposures. Philadelphia: WB Saunders; 2000.p. 486-93.

37. Best CH. Heparin and vascular occlusion. Can Med Assoc J. 1936;35:621-2. 
Appendix 1. Data collection form

\section{AXILLARY VEIN INJURY DURING LYMPHADENECTOMY-ASSOCIATED FACTORS}

\section{Patient's identification:}

Registration:[_____________ Age:[____ ] years old (in the date of diagnosis)

Date of the new case: $\mathrm{BMI}$

\section{Presence of palpable axillary metastasis at preoperative examination}

\section{Preoperative staging}

\section{Treatment}

\subsection{Surgery}

(1) Biopsy of the sentinel lymph node before lymphadenectomy

(2) Presence of axillary metastasis in the perioperative period

(3) Presence of axillary metastasis adhered to axillary vessels

(4) Size of axillary metastasis in the perioperative period

(5) Presence of pectoralis muscle invasion

(6) Preservation or section of the pectoralis major muscle

(7) Axillary incision separated from the breast incision

04.2 Radiotherapy prior to surgery

04.3 Neoadjuvant chemotherapy

05. Postoperative staging

Notes: 